\title{
AdJUVANTES e HeRbicidas e a Infectividade de Fusarium graminearum, Agente Potencial De Biocontrole De Egeria densa E Egeria najas ${ }^{1}$
}

\author{
Adjuvants and Herbicides and the Infectivity of Fusarium graminearum, a Potential Biocontrol \\ Agent of Egeria densa and Egeria najas
}

BORGES NETO, C.R. ${ }^{2}$ e PITELLI, R.A. ${ }^{3}$

\begin{abstract}
RESUMO - Foram estudados os efeitos da adição de adjuvantes e a associação com herbicidas na infectividade do fungo dentro do patossistema Fusarium graminearum x Egeria spp. Foram utilizadas plantas sadias de Egeria densa e E. najasinoculadas com uma suspensão de arroz moído colonizado por $F$. graminearum, na concentração de $0,7 \mathrm{~g} \mathrm{~L}^{-1}$. Os tubos de ensaio contendo as plantas imersas na referida suspensão foram mantidos em incubadora à temperatura de $25^{\circ} \mathrm{C}$ e fotoperiodo de 12 horas diárias de luz, por oito dias, durante os quais foram avaliados os sintomas nas plantas a cada dois dias e o crescimento destas através do incremento de matéria fresca ao final do experimento. O efeito de 14 adjuvantes e 6 herbicidas, adicionados à suspensão de inóculo, sobre a ação de $F$. graminearum em $E$. densa e E. najas foi avaliado. De modo geral, os adjuvantes melhoraram a eficiência do bioerbicida e a associação herbicida + fungo proporcionou maior severidade de doença e controle do crescimento das plantas.
\end{abstract}

Palavras-chave: bioerbicida, Elodea, macrófitas aquáticas submersas, controle biológico.

\begin{abstract}
The effects of adding adjuvants and their association with herbicides on fungus infectivity were studied in the Fusarium graminearum $x$ Egeria spp. pathosystem. Healthy Egeria densa and $\boldsymbol{E}$. naja plants were inoculated with suspension of ground rice with F. graminearum, at a concentration of $0.7 \mathrm{~g} \mathrm{~L}^{-1}$. The assay tubes with the plants immersed in the suspension were kept in the incubator at the temperature of $25^{\circ} \mathrm{C}$ and photoperiod of 12 hours daily, with plant symptoms being evaluated every two hours and plant growth monitored based on fresh matter increase at the end of the experiment. The effect of 14 adjuvants and 6 herbicides added to the inoculum on the action of $\boldsymbol{F}$. graminearum against $\boldsymbol{E}$. densa and $\boldsymbol{E}$. najas was evaluated. In general, the adjuvants improved bioherbicide efficiency and the herbicide + fungus association increased disease severity and plant growth control.
\end{abstract}

Key words: bioherbicide, Elodea, submerged aquatic macrophytes, biological control.

\section{INTRODUÇÃO}

As macrófitas são importantes componentes dos ecossistemas aquáticos, contribuindo com expressiva parcela da produtividade primária nesses ambientes, fornecendo abrigo para a reprodução e proteção de diversos organismos e promovendo heterogeneidade espacial que favorece a biodiversidade destes sistemas (Pitelli et al., 2000).

Recebido para publicação em 14.7.2003 e na forma revisada em 5.3.2004.

2 Doutor em Produção Vegetal, FCAVJ/UNESP; ${ }^{3}$ Prof. Titular Doutor do Dep. de Biologia Aplicada à Agropecuária, Faculdade de Ciências Agrárias e Veterinárias de Jaboticabal da Universidade Estadual Paulista - FCAVJ-UNESP, Via de Acesso Prof. Paulo Donato Castellane, s/no ${ }^{\circ}$ 14884-900 Jaboticabal-SP. 
Normalmente os problemas com macrófitas aquáticas ocorrem em corpos hídricos sob grande interferência humana, como rios represados, eutrofizados e com simplificação da biodiversidade (Pitelli et al., 2000). Plantas de Egeria densa e E. najas, membros da família Hydrocharitaceae, estão na lista das piores macrófitas aquáticas do Brasil, em razão dos problemas que vêm causando em reservatórios de usinas hidrelétricas, especialmente nos que suprem as Usinas de Souza Dias, no Estado de São Paulo; de Paulo Afonso, no Estado da Bahia; e a Estação Elevatória de Vigário, no Estado do Rio de Janeiro (Tanaka et al., 2002).

O controle biológico de plantas daninhas aquáticas é uma técnica que utiliza organismos vivos para controlar ou reduzir populações de espécies de plantas indesejáveis (Van Den Bosh et al., 1987). A estratégia de biocontrole de plantas invasoras denominada bioerbicida envolve o aumento da efetividade do organismo candidato, por meio de aplicações inundativas de esporos ou outros propágulos com a finalidade de gerar um alto nível de doença, com conseqüente morte ou supressão de populações da planta daninha em questão (Charudattan, 1991).

Um isolado de Fusarium graminearum temse mostrado patogênico às espécies anteriormente citadas (Nachtigal, 2000; Mendes, 2002; Borges Neto, 2003) e suficiente especificidade para que se avalie a possibilidade de seu desenvolvimento como agente de controle biológico. Este fungo vem sendo estudado no Laboratório de Controle Biológico de Plantas Daninhas "Prof. Dr. Giorgio de Marinis", da Faculdade de Ciências Agrárias e Veterinárias - FCAV da Universidade Estadual Paulista - UNESP, como agente de controle biológico pela estratégia inundativa (Nachtigal, 2000; Mendes, 2002).

A utilização de adjuvantes apropriados, bem como de formulações, é um meio para atenuar os efeitos adversos do ambiente sobre o fungo (Te Beest, 1991). Dentre os adjuvantes que vêm sendo pesquisados para formulações de micoerbicidas, destacam-se os surfatantes; as substâncias que fornecem nutrientes aos agentes de biocontrole; os protetores contra dissecação; e, finalmente, os inibidores de resistência da hospedeira, que geralmente são usados em emulsões invertidas (Amsellem et al., 1991; Womak \& Burge, 1993; Borges Neto et al., 1998). A utilização de herbicidas em associação com potenciais micoerbicidas no controle de macrófitas aquáticas tem sido estudada (Nelson et al., 1998; Getsinger et al., 2001; David et al., 2001); contudo, maior ênfase tem sido dada ao manejo integrado com a utilização de diversas técnicas de controle (Madsen, 2000; Krischik, 2002; Lembi, 2002).

Os estudos sobre a formulação de Fusarium graminearum para uso como bioerbicida estão em fase inicial, limitando-se aos trabalhos de Nachtigal (2000), Mendes (2002) e Borges Neto (2003). Ainda não existem estudos envolvendo a avaliação do efeito de adjuvantes e herbicidas, bem como a combinação destes com potenciais micoerbicidas, no controle de macrófitas aquáticas.

Neste trabalho foram avaliados a compatibilidade e os possiveis efeitos de diferentes adjuvantes e herbicidas sobre a ação de F. graminearum em plantas de Egeria densa e E. najas, tendo em vista sua possivvel utilização no manejo integrado destas macrófitas.

\section{MATERIAL E MÉTODOS}

O isolado FCAV\#940 de Fusarium graminearum foi utilizado neste trabalho. As colônias foram mantidas em tubos de ensaio contendo o meio BDA, sob refrigeração $\left(4^{\circ} \mathrm{C}\right)$. Para obtenção do inóculo, o fungo foi cultivado em arroz, conforme descrito por Nachtigal (2000).

As plantas utilizadas nos testes foram produzidas a partir de material propagativo proveniente do Reservatório da Usina Hidrelétrica de Três Irmãos, localizada no rio Tietê (20³9'S; 511' W), e do Reservatório da Usina Hidrelétrica Souza Dias, localizada no rio Paraná, em Jupiá-SP (2448'S; 511'W). Ponteiros de $8 \mathrm{~cm}$ de comprimento, de cada espécie, tiveram a massa fresca determinada, individualmente, após remoção do excesso de água da superficie das folhas por contato em papel absorvente. Os ponteiros foram transferidos para tubos de ensaio com $2,5 \mathrm{~cm}$ de diâmetro e $20 \mathrm{~cm}$ de comprimento. As plantas foram cultivadas em solução nutritiva de Clark modificada (Clark, 1975). 
A fim de avaliar os efeitos de adjuvantes adicionados ao inóculo sobre a severidade de doença causada por $F$. graminearum em $E$. densa e E. najas, foram testados 14 produtos (Tabela 1). Para verificação dos efeitos de herbicidas foram testados seis produtos (Tabela 1). Os ensaios com herbicidas foram conduzidos apenas com a espécie Egeria densa, pois, na época de sua realização, plantas-teste de E. najas não estavam disponiveis.

Para a inoculação, 0,7 g de arroz moído colonizado por $F$. graminearum foi suspenso em um litro de solução de Clark, onde foram adicionados os adjuvantes e herbicidas em suas respectivas concentrações (Tabela 1). Aliquotas de $50 \mathrm{~mL}$ dessa suspensão foram colocadas em tubos de ensaio, onde as plantas tiveram contato com o agente de controle biológico. Nas testemunhas, os procedimentos adotados foram os mesmos, mas foram utilizados apenas grãos de arroz moídos, sem colonização pelo fungo, totalizando 16 tratamentos no ensaio com adjuvantes e 14 no ensaio com herbicidas. Após a inoculação, as plantas foram transferidas para incubadoras para BOD, com temperatura de $25^{\circ} \mathrm{C}$ e fotoperíodo de 12 horas diárias de luz.

As avaliações da severidade de doença foram realizadas a cada dois dias, até o sexto dia após a inoculação no experimento com adjuvante e até o oitavo dia após a inoculação no experimento com herbicidas, com o auxílio

Tabela 1 - Adjuvantes e herbicidas avaliados quanto aos seus efeitos na severidade de doença causada por Fusarium graminearum em plantas de Egeria densa e E. najas

\begin{tabular}{|c|c|c|c|}
\hline Nome Comercial & Princípio Ativo & Função & $\begin{array}{c}\text { Dose } / 100 \mathrm{~L} \\
\text { de calda }\end{array}$ \\
\hline 1. Agral ${ }^{\circledR}$ & Nonil fenoxi poli (etilenoxi) etanol $200 \mathrm{~g} \mathrm{~L}^{-1}$ & $\begin{array}{l}\text { Surfatante, } \\
\text { espalhante adesionante }\end{array}$ & $30 \mathrm{~mL}^{1 /}$ \\
\hline 2. Aterbane $\mathrm{BR}{ }^{\circledR}$ & $\begin{array}{l}\text { Condensado de alcoolfenóis+óxido de eteno+sulfonatos orgânicos } \\
460 \mathrm{~g} \mathrm{~L}^{-1}\end{array}$ & Espalhante adesionante & $250 \mathrm{~mL}^{1 /}$ \\
\hline 3. Citowett $200^{\circledR}$ & Poli-oxietileno-alquil-fenol éter $200 \mathrm{~g} \mathrm{~L}^{-1}$ & Espalhante adesionante & $150 \mathrm{~mL}^{\mathrm{L}}$ \\
\hline 4. Energic ${ }^{\circledR}$ & $\begin{array}{l}\text { Nonil fenoxi poli (etilenoxi) etanol } 226 \mathrm{~g} \mathrm{~L}^{-1}+\text { sal sódico do ácido } \\
\text { dodecil benzeno sulfônico } 226 \mathrm{~g} \mathrm{~L}^{-1}\end{array}$ & $\begin{array}{l}\text { Surfatante, } \\
\text { espalhante adesionante }\end{array}$ & $200 \mathrm{~mL}^{1 /}$ \\
\hline 5. Haiten ${ }^{\circledR}$ & Polioxietileno alquil fenol éter $200 \mathrm{~g} \mathrm{~L}^{-1}$ & Espalhante adesionante & $15 \mathrm{~mL}^{\frac{1}{1}}$ \\
\hline 6. Herbitensil ${ }^{\circledR}$ & Nonil fenol oxietilado $400 \mathrm{~g} \mathrm{~L}^{-1}+$ álcool isopropílico $150 \mathrm{~g} \mathrm{~L}^{-1}$ & Espalhante & $150 \mathrm{~mL}^{1 /}$ \\
\hline 7. Iharaguen-S® & Polioxietileno alquil fenol éter $200 \mathrm{~g} \mathrm{~L}^{-1}$ & Espalhante adesionante & $10 \mathrm{cc}^{1 /}$ \\
\hline 8. Natur’l Óleo ${ }^{\circledR}$ & $\begin{array}{l}\text { Ésteres de ácidos graxos com glicerol } 930 \mathrm{~mL} \mathrm{~L}^{-1}+\text { ingredientes } \\
\text { inertes } 70 \mathrm{~mL} \mathrm{~L}^{-1}\end{array}$ & Adesionante, inseticida & $1,5 \mathrm{~L}^{1 /}$ \\
\hline 9. Visóleo $800 \circledR$ & Hidrocarbonetos parafínicos $800 \mathrm{~g} / \mathrm{L}+$ ingredientes inertes $200 \mathrm{~g} \mathrm{~L}^{-1}$ & Adesionante, inseticida & $1,5 \mathrm{~L}^{1 /}$ \\
\hline 10. Tween 80 & Polioxietileno monolaurático & Surfatante & $20 \mathrm{~mL}^{\frac{2}{1}}$ \\
\hline 11. Sacarose & Sacarose $\left(\mathrm{C}_{6} \mathrm{H}_{22} \mathrm{O}_{11}\right)$ & Fonte de carbono & $2 \mathrm{~kg}^{3 /}$ \\
\hline 12. Dextrose & D-glucose anidra $\left(\mathrm{C}_{6} \mathrm{H}_{12} \mathrm{O}_{6}\right)$ & Fonte de carbono & $2 \mathrm{~kg}^{3 /}$ \\
\hline 13. Amido & Amido solúvel & Fonte de carbono & $2 \mathrm{~kg}^{3 /}$ \\
\hline 14. Metamucil & Mucilóide hidrófilo de Psyllium plantago & Umectante & $0,5 \mathrm{~kg}^{1 /}$ \\
\hline 1. Ácido acético glacial & $\mathrm{CH}_{3} \mathrm{COOH} ; \mathrm{PM}=60,05 \mathrm{~g} \mathrm{~mol}^{-1} ; 1 \mathrm{~L}=1,05 \mathrm{~kg}$ & Algicida & $0,5 \mathrm{ppm}^{4 /}$ \\
\hline 2. Ácido cítrico monoidratado & $\mathrm{C}_{6} \mathrm{H}^{8} \mathrm{O}_{7}-\mathrm{H}_{2} \mathrm{O} ; \mathrm{PM}=210,14$ & Algicida & $0,5 \mathrm{ppm}^{4 /}$ \\
\hline 3. Sulfato de cobre & $\mathrm{CuSO}_{4}-5 \mathrm{H}_{2} \mathrm{O} ; \mathrm{PM}=249,68$ & Algicida & $0,02 \mathrm{ppm}^{4 /}$ \\
\hline 4. Garlon ${ }^{\circledR}$ & $\begin{array}{l}\text { Tryclopyr, éster butox etílico } 667 \mathrm{~g} \mathrm{~L}^{-1} \text {. Equivalente ácido do } \\
\text { Tryclopyr } 480 \mathrm{~g} \mathrm{~L}^{-1} \text {, Grupo dos Piridiloxilacéticos }\end{array}$ & Herbicida & $1,5 \mathrm{~L} / \mathrm{ha}^{4}$ \\
\hline 5. Reward ${ }^{\circledR}$ & $\begin{array}{l}\text { 1,1'-etileno-2,2-bipiridilium íon, (Diquat) dibrometo, Grupo dos } \\
\text { Bipiridílios }\end{array}$ & Herbicida & $2,0 \mathrm{~L} \mathrm{ha}^{-14 /}$ \\
\hline 6. Sonar A.S. ${ }^{\circledR}$ & $\begin{array}{l}\text { 1-metil-3-fenil-5-[3-(triflurometil) fenil] -4 }(1 \mathrm{H}) \text { - piridione } 41,7 \% \text {, } \\
\text { Fluridone }\end{array}$ & Herbicida & $0,09 \mathrm{ppm}^{4}$ \\
\hline
\end{tabular}

${ }^{1 /}$ Organização Andrei Editora Ltda. (1996); ${ }^{2 /}$ Borges Neto et al. (1998); ${ }^{3 /}$ Amsellem et al. (1991), Borges Neto et al. (1998); ${ }^{4 /}$ Madsen (2000). Krischik (2002). Lembi (2002). 
da escala de notas proposta por Nachtigal (2000), a saber: nota 1: clorose aparente e não superior a $5 \%$ do tamanho da brotação; nota 3: amarelecimento foliar visivel e conspícuo na porção basal ou, eventualmente, na porção superior, não afetando mais de $20 \%$ do tamanho da brotação; nota 5: amarelecimento moderado, afetando os tecidos até a porção mediana ou terço superior das brotações; nota 7: severo amarelecimento do caule e de mais de $80 \%$ da área foliar, flacidez dos tecidos vegetais e, eventualmente, abscisão dos segmentos terminais; e nota 9: amarelecimento generalizado com completa desintegração dos tecidos vegetais. Notas intermediárias correspondem à média das notas especificadas. A porcentagem de incremento na massa fresca das plantas foi calculada pela diferença de peso fresco antes da montagem dos experimentos e após o término destes.

O delineamento experimental adotado foi o de blocos ao acaso, com três repetições. Todos os ensaios foram repetidos três vezes no tempo, constituindo os blocos do delineamento. Em cada época de montagem dos ensaios, cada tratamento teve cinco tubos de ensaio e foi utilizada a média das notas e da porcentagem de massa fresca obtidas nas avaliações para constituir o dado de cada parcela experimental. Os resultados foram submetidos à análise de variância e ao teste de Tukey, para comparação de médias. Nas análises estatísticas, os dados de porcentagem de ganho de massa fresca foram transformados em arc-seno $\sqrt{x} / 100$. As análises foram feitas utilizando-se o programa Origin ${ }^{\circledR} 6.0$.

\section{RESULTADOS E DISCUSSÃO}

Observando os resultados obtidos, pode-se verificar que a severidade de doença em plantas de Egeria densa e de E. najas (Tabela 2) foi afetada de forma significativa pelos diversos tratamentos.

$\mathrm{Na}$ avaliação dos sintomas aos dois dias após a inoculação, os tratamentos contendo o inóculo fúngico adicionados aos espalhantes adesionantes Energic ${ }^{\circledR}$ e Aterbane $B R \AA$ e o umectante Metamucil apresentaram maiores notas relativas à severidade de doença (Tabela 2), com diferença significativa para a espécie E. najas, em todos os períodos de avaliação. No quarto dia, destacaram-se os mesmos produtos adicionados ao inóculo; entretanto, não houve diferença estatística entre os tratamentos com os referidos adjuvantes para $E$. densa, o que não ocorreu com E. najas (Tabela 2). Já no sexto dia de avaliação, além dos produtos citados, destacaram-se os espalhantes Agral $®$ e Iharaguen-S $₫$ e as fontes de carbono sacarose e dextrose para $E$. densa (Tabela 2). No caso de E. najas, destacaram-se os adjuvantes Aterbane BR ${ }^{\circledR}$, Energic ${ }^{\circledR}$, dextrose e Metamucil (Tabela 2). A espécie $E$. densa parece ser mais sensivel aos adjuvantes adicionados ao inóculo do que $E$. najas.

Nos tratamentos em que apenas os adjuvantes foram adicionados à suspensão de inóculo não houve interferência de forma significativa no desenvolvimento das plantas, exceto nos caso das fontes de carbono, por aumentarem a Demanda Bioquímica de Oxigênio (DBO), e do umectante Metamucil, que a partir de quatro horas após o preparo da solução formou uma substância gelatinosa na superfície, impedindo o bom desenvolvimento das plantas. Com relação ao ganho de biomassa, as maiores restrições de crescimento das plantas de E. densa foram observadas nos tratamentos em que os espalhantes Aterbane BR $\AA$, Energic ${ }^{\circledR}$, Herbitensil ${ }^{\circledR}$ e Agral ${ }^{\circledR}$ foram adicionados ao inóculo (Tabela 2); nos tratamentos com os dois primeiros produtos não houve crescimento das plantas - o mesmo ocorreu com E. najas (Tabela 2) para os referidos produtos.

Os produtos herbicidas e suas associações com $F$. graminearum passaram a exercer maior interferência no desenvolvimento de sintomas a partir do quarto dia de avaliação (Tabela 3), em plantas de E. densa.

De modo geral, a associação herbicida+fungo apresentou maior severidade de doença. As melhores associações, aos oito dias de avaliação, foram Reward ${ }^{\circledR}+$ fungo, Garlon ${ }^{\circledR}+$ fungo e Sonar ${ }^{\circledR}+$ fungo, diferindo estatisticamente das demais associações e tratamentos (Tabela 3). Com relação à produção de matéria fresca, as referidas associações e o tratamento com ácido acético praticamente impediram as plantas de se desenvolverem vegetativamente. 
Tabela 2 - Influência de adjuvantes adicionados ao inóculo na severidade de doença causada por Fusarium graminearum em plantas de Egeria densa e E. najas e na produção de matéria fresca destas macrófitas

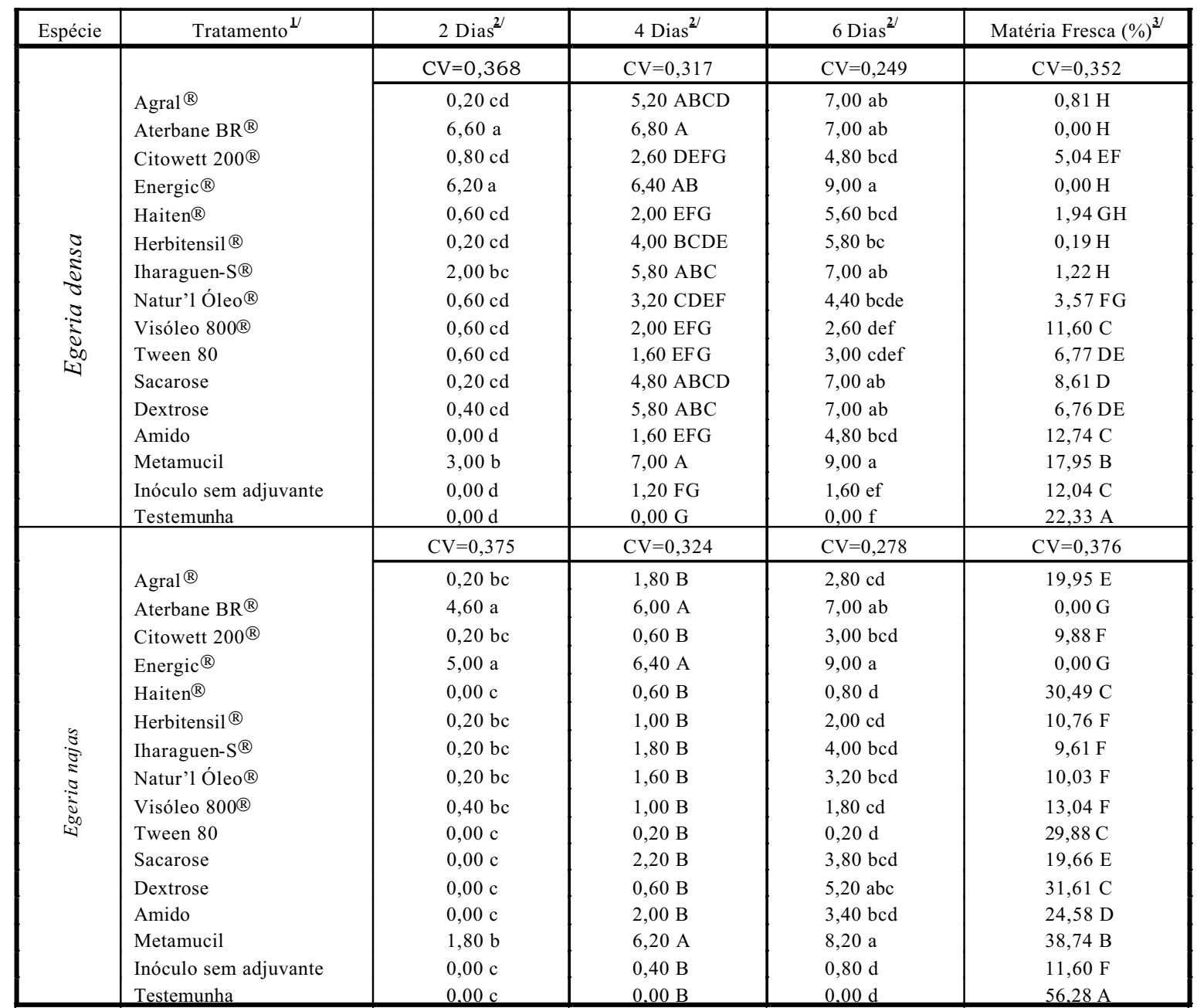

1/ Tratamentos em que apenas os adjuvantes foram adicionados à suspensão não interferiram de forma significativa no desenvolvimento das plantas; ' Média das notas dadas aos sintomas, proposta por Nachtigal (2000); ${ }^{3 /}$ Porcentagem de aumento da matéria fresca das plantas-teste.

Médias seguidas da mesma letra, nas colunas, não diferem entre si pelo teste de Tukey a 5\% de probabilidade, em cada avaliação (2, 4 e 6 dias; matéria fresca - \%).

As populações de plantas aquáticas submersas são dificeis de manejar ou controlar. O hábito perene de crescimento e a formação de colonizações monofiticas parecem torná-las alvo ideal para a adoção de medidas de controle químico ou biológico, porém essas medidas de controle são freqüentemente comprometidas por problemas relacionados ao ambiente aquático, incluindo a diluição e o tempo de contato em água corrente (Nelson et al., 1998). Daí a necessidade de se avaliar, como adjuvantes para a formulação de $F$. graminearum, um maior número de produtos que sejam agentes surfatantes combinados com substâncias adesivas que possam espalhar uniformemente o inóculo no perfil d'água e mantê-lo próximo e/ou aderido às superficies das plantas. A utilização de herbicidas em consórcio com os agentes de biocontrole também deve ser estudada. 
Tabela 3 - Influência de herbicidas adicionados ao inóculo na severidade de doença causada por Fusarium graminearum de plantas de Egeria densa e na produção de matéria fresca desta macrófita

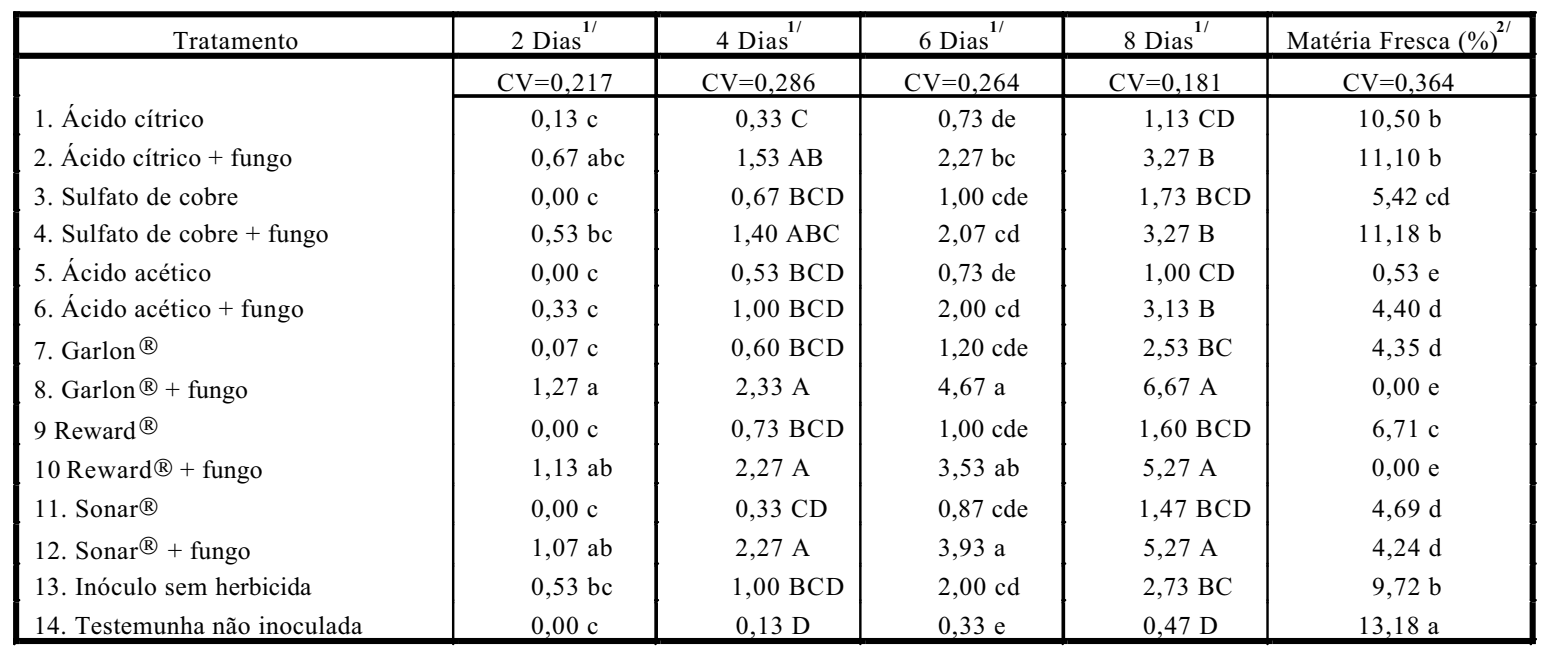

${ }^{1}$ Média das notas dadas aos sintomas, proposta por Nachtigal (2000).

${ }^{2 /}$ Porcentagem de aumento da matéria fresca das plantas-teste.

Médias seguidas da mesma letra, nas colunas, não diferem entre si pelo teste de Tukey a 5\% de probabilidade, em cada avaliação (2, 4 , 6 e 8 dias; matéria fresca- \%).

A utilidade de emulsões, umectantes, surfatantes, estimulantes e outros adjuvantes depende das características fisiológicas e morfológicas do patógeno, da planta e de características do meio ambiente (Van Dyke \& Trigiano, 1987). De acordo com Womak \& Burge (1993), o uso de adjuvantes nas formulações de bioerbicidas pode melhorar a ação do agente de biocontrole de diversas maneiras: promovendo melhor distribuição e adesão do inóculo; induzindo o crescimento de tubos germinativos e estruturas infectivas; quebrando a resistência do hospedeiro; e protegendo os propágulos da influência das condições ambientais adversas.

Existem, na literatura, várias referências sobre formulações baseadas no uso de surfatantes (Amsellem et al., 1991), substâncias fornecedoras de nutrientes (Amsellem et al., 1991) e umectantes (Womak \& Burge, 1993). O uso de aditivos em formulações de bioerbicidas requer precauções, principalmente no tocante ao uso de emulsões invertidas. No controle biológico de plantas terrestres, Amsellem et al. (1991) observaram alteração na seletividade de Alternaria cassiae, agente de biocontrole de Senna obtusifolia. A cultura da soja foi afetada pelo fungo, e as hipóteses levantadas para explicar essa perda de seletividade do bioerbicida foram os danos físicos à cutícula das folhas pelo agente emulsificante e a supressão das defesas naturais da planta. O mesmo pode ocorrer em ambientes aquáticos, uma vez que os produtos adicionados ao inóculo podem afetar outras plantas, bem como a própria qualidade da água.

Os adjuvantes Agral ${ }^{\circledR}$, Aterbane $B R \AA$, Citowett $200 \AA$, Energic $\AA$, Haiten $₫$, Herbitensil $\AA$, Iharaguen-S ${ }^{\circledR}$, Natur'l Óleo ${ }^{\circledR}$ e Visóleo $800 \circledR$ não interferiram de forma expressiva no crescimento de $F$. graminearum in vitro, porém alguns dos adjuvantes testados exerceram ação fungistática (Borges Neto, 2003). Com relação aos herbicidas, apenas dois produtos interferiram no crescimento de $F$. graminearum: o sulfato de cobre na concentração de 0,2 ppm e o ácido acético na concentração de 5 ppm (Borges Neto, 2003).

Verificou-se que a severidade de doença foi afetada de forma significativa pelos espalhantes adesionantes Energic $\AA$, Aterbane BR $₫$, Agral ${ }^{\circledR}$ e Iharaguen- $\mathrm{S} \AA$, pelo umectante Metamucil e pelas fontes de carbono sacarose e dextrose, para $E$. densa; no caso de E. najas, destacaramse Haiten ${ }^{\circledR}$, Tween 80 e Metamucil. 
Com relação ao ganho de peso, as maiores restrições de crescimento das plantas de ambas as espécies foram observadas para os tratamentos que envolveram os espalhantes Agral ${ }^{\circledR}$, Aterbane ${ }^{\circledR}$, Energic ${ }^{\circledR}$ e Herbitensil ${ }^{\circledR}$.

A associação herbicida+fungo promoveu maior severidade de doença, destacando-se as associações Reward $\AA+$ fungo, Garlon $\AA+$ fungo e Sonar ${ }^{\circledR}+$ fungo. A produção de massa fresca adicional foi praticamente impedida pelas associações Reward ${ }^{\circledR}+$ fungo, Garlon ${ }^{\circledR}+$ fungo e o tratamento com ácido acético.

\section{LITERATURA CITADA}

AMSELLEM, Z.; SHARON, A.; GRESSEL, J. Abolition of selectivity of two mycoherbicidal organisms and enhanced virulence of avirulent fungi by an invert emulsion.

Phytopathol., v. 81, n. 9, p. 985-988, 1991.

BORGES NETO, C. R. Estudo do potencial de Fusarium graminearum como agente de controle biológico de Egeria densa e E. najas. 2003. 126 f. Tese (Doutorado em Produção Vegetal) - Universidade Estadual Paulista, Jaboticabal, 2003.

BORGES NETO, C. R. et al. Efeito de adjuvantes no crescimento e infectividade do fungo Cercospora caricis, agente de biocontrole da tiririca. Fitopatol. Bras., v. 23, n. 4, p. 502, 1998.

CHARUDATTAN, R. The mycoherbicide approaches with plant pathogens. In: TE BEEST (Ed.) Microbial control of weeds. New York: Chapman and Hall, 1991. p. 24-57.

CLARK, R. B. Characterization of phosphate of intact maize roots. J. Agric. Food. Chem., v. 23, p. 458-460, 1975.

DAVID, G. P. et al. The aquatic fate of triclopyr in wholepond treatments. Pest Manag. Sci., v. 57, p. 764-775, 2001. Disponível em $<\mathrm{http}: / /$ www.aquatics.org $>$. Acesso em 31 jan. 2002.

GETSINGER, K. D. et al. Whole-lake applications of sonar for selective control of eurasian watermilfoil. US Army Corps of Engineers, Waterways Experiment Station. ERDC/EL Technical Report 01-7, 2001. Disponível em $<\mathrm{http}: / /$ www.aquatics.org $>$. Acesso em 31 jan. 2002.

KRISCHIK, V. A. Managing aquatic plants in Minnesota lakes. University of Minnesota. Disponível em $<$ http:// www.extension.umn.edu/distribution/horticulture / DG6955.html>. Acesso em 31 jan. 2002.
LEMBI, C. A. Aquatic plant management. Purdue University, Cooperative Extension Service, West Lafayette, IN 47907. Disponível em <http:// persephone.agcom.purdue.edu/AgCom/Pubs/WS/WS21.html>. Acesso em 31 jan. 2002.

MADSEN, J. D. Advantages and disadvantages of aquatic plant management techniques. LakeLine, v. 20, n. 1, p. 2234, Spring 2000. Disponível em $<\mathrm{http} / /$ www.aquatics.org/ pubs/madsen.htm>. Acesso em 31 jan. 2002.

MENDES, D. Efeitos de herbicidas sobre alguns aspectos biológicos de Fusarium graminearum (isolado FCAV\#940), agente potencial de controle biológico de Egeria densa e Egeria najas. 2002. 110 f. Dissertação (Mestrado em Produção Vegetal) - Universidade Estadual Paulista, Jaboticabal, 2002.

NACHTIGAL, G. F. Desenvolvimento de agente de controle biológico microbiano de Egeria densa e Egeria najas. 2000. $160 \mathrm{f}$. Tese (Doutorado em Produção Vegetal) - Universidade Estadual Paulista, Jaboticabal, 2000.

NELSON, L. S.; SHEARER, J. F.; NETHERLAND, M. D. Mesocosm evaluation of integrated fluridone-fungal pathogen treatment on four submersed plants. J. Aquatic Plant Manag., v. 36, p. 73-77. 1998

ORGANIZAÇÃO ANDREI EDITORA Ltda. Compêndio de defensivos agrícolas: Guia prático de produtos fitossanitários para uso agrícola. São Paulo: 1996. 506 p.

PITELLI, R. A.; PITELLI, R. L. C. M.; MARCONDES, D. A. S. Controle biológico de macrófitas aquáticas. In: WORKSHOP ECOLOGIA E MANEJO DE MACRÓFITAS AQUÁTICAS, 2000, Maringá. Resumos... Maringá: Sociedade Brasileira de Limnologia, UEM, Nupelia, PEA, ELETROBRÁS, 2000. p. 23.

TANAKA, R. H. et al. Avaliação de herbicidas para o controle de Egeria em laboratório, caixa d'água e represa sem fluxo de água. Planta Daninha, v. 20, p. 73-81, 2002.

TE BEEST, D. O. Microbial control of weeds. New York: Chapman and Hall, 1991. 284 p.

Van Den BOSH, R.; MESSENGER, P. S.; GUTIERREZ, A. An introduction to biological control. New York: Plenum Press, 1987. $247 \mathrm{p}$.

Van DIKE, C. G.; TRIGIANO, R. N. Light and scaning electron microscopy of the interaction of the biocontrol fungus Alternaria cassiae with sicklepood (Cassia obtusifolia). Can. J. Plant Pathol., v. 9, p. 230-235, 1987.

WOMAK, J. G.; BURGE, M. N. Mycoherbicide formulation and the potential bracken control. Pestic. Sci., v. 37, p. $337-341,1993$. 